\title{
UMA ANÁLISE DA RAZÃO DE ESTADO EM MICHEL FOUCAULT A PARTIR DO CURSO SEGURANÇA, TERRITÓRIO E POPULAÇÃO
}

An analysis of reasos in state of Michel Foucault from course of Security, Territory and Population

Odair Camati *

Resumo: O presente artigo visa apresentar o conceito de razão de Estado a partir do curso de Michel Foucault Segurança, território $e$ população proferido no Collège de France em 1978. Utilizando-se do método genealógico o pensador francês faz uma análise do que chama de governamentalidade, ou seja, da passagem do governo das almas para o governo político dos homens. Desse modo, partindo do poder pastoral o pensador francês apresenta os elementos que possibilitaram o surgimento de novas técnicas de governo, ou o que modernamente foi denominado razão de Estado.

Palavras-chave: Governamentalidade. Poder pastoral. Razão de Estado

\begin{abstract}
This article presents the concept of reason of state from the course of Michel Foucault Security, territory and population delivered at the Collège de France in 1978. Utilizing the genealogical method the French thinker makes an analysis of what he calls governmentality, in other words, the passage of the government of souls to the political government of men. Thus, starting from the pastoral power the French thinker presents the elements that enabled the emergence of new techniques of government, or what was called modern reason of state.
\end{abstract}

Keywords: Governmentality. Pastoral power. Reason of State.

\footnotetext{
* Doutorando do Programa de Pós-graduação em Filosofia da Universidade do Vale dos Sinos(UNISINOS). Email: odcamati@ hotmail.com
}

\begin{tabular}{|c|c|c|c|c|c|}
\hline intuitio & $\begin{array}{c}\text { ISSN } \\
1983-4012\end{array}$ & Porto Alegre & Vol.8 $-\mathrm{N}^{\mathrm{o}} .1$ & $\begin{array}{c}\text { Junho } \\
2015\end{array}$ & p.171-184 \\
\hline
\end{tabular}


Odair Camati

Uma análise da razão de estado em Michel Foucault a partir do curso Segurança, Território e População

\section{Introdução}

Foucault no curso Segurança, território e população (1978) faz uma análise do biopoder, ou "poder sobre a vida", e de como a ação governamental passou da disciplina corporal na sociedade disciplinar para a população enquanto objeto de políticas governamentais. População entendida aqui como um sujeito de necessidades que deve ser conduzida pelo governo. Nesse sentido, o governo moderno não está mais preocupado com o território, sua preocupação se dirige à população, logo há uma mudança de ênfase na ação governamental. Nosso objetivo nesse texto se reduz à análise da referida obra de Foucault, desse modo, não temos a pretensão de esgotar o tema, pelo contrário, buscamos apenas apresentar algumas pistas de interpretação a partir de Segurança, território e população.

Utilizando-se do método genealógico o filósofo francês realiza uma incursão histórica a fim de compreender o que chama de governamentalidade. O método genealógico de Foucault busca despir as verdades das máscaras históricas a fim de mostrar as verdades que subjazem as práticas históricas e com isso possibilitar a consciência crítica das verdades que comumente professamos e até mesmo das nossas práticas mais comuns. É importante não perder de vista a metodologia de Foucault para não nos perdermos nas várias análises históricas pontuais presentes em suas obras.

\section{O poder pastoral}

O conceito de governamentalidade criado por Foucault não remonta como nos pareceria à primeira vista a teoria política clássica, mas ao que o filósofo francês convencionou chamar de poder pastoral, esse argumento é central para a compreensão de Razão de Estado, desse modo será aprofundado no decorrer do texto. Nessa discussão, é imprescindível que tomemos o conceito de governamentalidade, segundo André Duarte, “instrumento heurístico para a investigação da racionalidade das práticas de controle, vigilância e intervenção governamental sobre os fenômenos populacionais, funcionando, ademais, como recurso analítico para a discussão das práticas de governamento de tipo especificamente liberal." ' ${ }^{1}$ Nesse sentido, a noção grega não é dominante na modernidade, pois os gregos entendiam o governo como governo da cidade e não das pessoas, exatamente o oposto da noção moderna de governo que tem como princípio básico o governo das pessoas.

Ainda nessa esteira argumentativa, os gregos "inventaram" a política com ao menos três princípios básicos: espaço para a autonomia individual; espaço para a decisão coletiva e o princípio da

${ }^{1}$ DUARTE, André de Macedo. Foucault e a governamentalidade: genealogia do liberalismo e do Estado Moderno. In: SelectedWords, 2011, p.2.

\begin{tabular}{|c|c|l|l|l|l|}
\hline intuitio & $\begin{array}{c}\text { ISSN } \\
1983-4012\end{array}$ & Porto Alegre & Vol.8 $-\mathrm{N}^{\mathrm{o} .1}$ & $\begin{array}{c}\text { Junho } \\
2015\end{array}$ & p.171-184 \\
\hline
\end{tabular}


isonomia (os iguais são tratados igualmente). Esses princípios para Foucault não dão conta de explicar as modernas técnicas de governo, visto que ainda não colocam em primeiro plano o governo político dos indivíduos. É somente o poder pastoral que possui os germes para o surgimento da noção moderna de governo. Afirma Foucault:

Que o pastorado cristão introduziu um jogo que nem os gregos nem os hebreus haviam imaginado. Estranho jogo cujos elementos são a vida, a morte, a verdade, a obediência, os indivíduos, a identidade; jogo que parece não ter relação alguma com o da cidade que sobrevive através do sacrifício dos seus cidadãos. ${ }^{2}$

As discussões sobre as relações entre pastor e o comando das ovelhas entraram perifericamente no pensamento grego através da escola pitagórica, contudo, essas práticas nunca foram adotadas pela política grega. Platão no diálogo, $O$ Político, trata da questão do pastorado, mas para o filósofo grego somente a divindade ao comandar homens é pastor, homens que comandam homens - os políticos - fazem parte da humanidade e com isso não estão acima de seus comandados, consequentemente não podem ser considerados pastores. Platão então propõe o modelo do tecelão, pois o político deve tecer a multiplicidade dos fios que constitui os seus comandados, construindo sempre o bem comum. Desse modo, fica claro que entre os gregos o modelo do pastorado serve apenas às pequenas comunidades, visto que o rei tem de ser tecelão e não pastor.

O poder pastoral é um poder do cuidado do outro, ou seja, busca individualizar o cuidado. A preocupação não é mais com a cidade, mas com o indivíduo particular. A noção de cuidado individual também não estava presente entre os gregos, pois o importante era o governo da cidade e o bem comum. É somente com a noção de pastorado, especialmente do pastorado cristão, que surge a necessidade de um cuidado individual. O pastor é responsável por todo o rebanho, mas também por cada ovelha em particular. Como afirma Rone dos Santos, “o poder pastoral era ao mesmo tempo totalizante e individualizante já que o pastor devia cuidar de todo rebanho e em particular de cada uma das ovelhas"3. Foucault ao tratar das diferenças do pastorado cristão com relação ao pastorado hebraico ou oriental, afirma:

[...] o pastorado no cristianismo deu lugar toda uma arte de conduzir, de dirigir, de levar, de guiar, de controlar, de manipular os homens, uma arte de segui-los e de empurrá-los passo a passo, uma arte que tem a função de encarregar-se dos

\footnotetext{
${ }^{2}$ FOUCAULT, Michel. "Omnes et singulatim": vers une critique de la raison politique. In.: Dits et Écrits. Vol. IV. Editado por D. Defert, F. Ewald e J. Lagrange. Paris: Gallimard, 1994, p. 147.

${ }^{3}$ SANTOS, R. Eleandro dos. Do governo pastoral à governamentalidade: crítica da razão política em Michel Foucault. In: Poros, vol. 1, n. 2, 2009, p17.
}

\begin{tabular}{|c|c|c|c|c|c|}
\hline intuitio & $\begin{array}{c}\text { ISSN } \\
1983-4012\end{array}$ & Porto Alegre & Vol.8 $-\mathrm{N}^{\circ} .1$ & $\begin{array}{c}\text { Junho } \\
2015\end{array}$ & p.171-184 \\
\hline
\end{tabular}


homens coletiva e individualmente ao longo de toda a vida deles e a cada passo de sua existência. ${ }^{4}$

O pastorado cristão é, então, uma arte de governar os homens, diferente do que apareceu no Oriente. Para marcar ainda mais essa diferença Foucault relaciona o pastorado cristão com três temas, a salvação, a lei e a verdade. Em primeiro lugar o pastor deve se preocupar com a salvação de todos, mas também de cada um em particular. Nenhuma ovelha pode escapar da condução que a leva à salvação. Em sendo responsável por cada ovelha, no final o pastor deve prestar conta de todas, nesse sentido, é responsável pela perda possível de uma das ovelhas e irá responder por isso. Essa relação é tão estreita que Foucault afirma "o mal que sucede à ovelha ou que ocorre através da ovelha ou por causa dela, o pastor deverá considerá-lo também como acontecendo com ele próprio ou que ele mesmo faz." 5

Segundo, o pastorado cristão instaura o que Foucault chama de "obediência pura", pois o cristianismo é uma religião da vontade de Deus para cada um em particular. O pastor não constitui o homem da lei, ele apenas aplica a lei divina para cada caso em particular, podemos dizer que é uma espécie de médico que visa recuperar a ovelha que por ventura se desvie do caminho divino. A obediência à Deus deve acontecer em toda e qualquer situação, mesmo que a ovelha tenha que ir contra uma lei humana, ela deve obedecer, pura e simplesmente. Nesse sentido, há um rompimento com a lei humana e uma necessidade de cega obediência. Na obediência do pastorado não há finalidade, há simplesmente a obediência da vontade divina.

Por fim o pastorado se relaciona com a verdade. O pastor tem uma tarefa de ensino para com sua comunidade, pois o encargo do bispo é ensinar. Contudo, não se trata apenas de um ensino doutrinal, o pastor deve ensinar também a partir de seu exemplo. Além disso, o ensino não acontece de forma geral, visto que cada ovelha necessita de um ensinamento específico, novamente aqui percebemos como o pastorado cristão introduz uma forte noção de individuação. Esse aspecto se torna ainda mais evidente a partir de dois elementos presentes no ensino do pastor, a direção da conduta cotidiana e a direção da consciência da ovelha. Ensinar a partir da conduta cotidiana e dirigir a consciência significa que o acompanhamento pastoral deve ser próximo e constante.

Portanto, o tema do pastorado é importante para Foucault, pois, é a partir do pastorado que podemos falar de governamentalidade. No pastorado cristão temos fortemente a noção de conduta, ou seja, as ovelhas devem ser conduzidas de perto e continuamente, como ficou claro na relação existente entre o pastorado e a verdade que acima apresentamos. São os movimentos de contraconduta que permitem a

\footnotetext{
${ }^{4}$ FOUCAULT, M. Segurança, território, população. Trad. Eduardo Brandão. São Paulo: Martins Fontes, 2008 , p. 218-219.

${ }^{5}$ FOUCAULT, M. Segurança, território, população. Trad. Eduardo Brandão. São Paulo: Martins Fontes, 2008 , p. 225.
}

\begin{tabular}{|c|c|c|c|c|c|}
\hline intuitio & $\begin{array}{c}\text { ISSN } \\
1983-4012\end{array}$ & Porto Alegre & Vol.8 $-\mathrm{N}^{\mathrm{o}} .1$ & $\begin{array}{c}\text { Junho } \\
2015\end{array}$ & p.171-184 \\
\hline
\end{tabular}


passagem da "pastoral das almas ao governo político dos homens" movimentos de contraconduta que lutam contra os procedimentos utilizados para conduzir os outros. São eles: o ideal asceta do domínio de si; a desconfiança do poder sacramental; as experiências míticas que escapam do poder pastoral; o retorno aos textos das Escrituras e a crença escatológica no retorno de Cristo. Tais movimentos de contraconduta serão retomados e tematizados na seção seguinte.

\section{A razão de Estado}

A análise de Foucault se direciona sempre às práticas que permitem o surgimento de novas instituições. Nesse sentido, o movimento de contraconduta permite o surgimento da noção de governamentalidade e consequentemente a noção moderna de Estado. O pastorado cristão é para Foucault o elemento de conexão de práticas exteriores, ou seja, entre as crises econômicas de um lado e os temas religiosos de outro. O pastorado é uma espécie de fio que permite analisar o surgimento da governamentalidade sem perder de vista os elementos econômicos, políticos e religiosos presentes nesse processo. É o que afirma Michel Senellart:

A implementação de técnicas pastorais no quadro do aparelho de Estado: tal era: para Foucault, a matriz da razão política moderna. Propunha então chamar com a estranha palavra 'governabilidade' o processo que tinha conduzido da pastoral cristã ao Estado de polícia e que se prolongará até nós. O ‘governo’ não era a simples instrumentalização da força de um Estado cada vez mais compacto, mas uma figura original do poder, articulando técnicas específicas de saber, de controle e de coerção. Uma certa racionalização, pois, historicamente definida, das relações de poder. ${ }^{7}$

A passagem do governo das almas ao governo político dos homens é demarcada por Foucault numa grande linha de resistências, revoltas e insurreições de conduta. Afirma o pensador francês:

[...] no curso do século XVI não se assiste a um desaparecimento do pastorado. Não se assiste nem mesmo à transferência maciça e global das funções pastorais da Igreja para o Estado. Assiste-se, na verdade, a um fenômeno muito mais complexo que é o seguinte. De um lado, podemos dizer que há uma intensificação do pastorado religioso, intensificação desse pastorado em suas formas espirituais, mas também em sua extensão e em sua eficiência temporal. [...] Por outro lado, assiste-se também, no século XVI, a um desenvolvimento da condução dos homens fora até da autoridade eclesiástica, e aqui também sob dois aspectos ou, mas exatamente, sob toda uma série de aspectos que constituem

\footnotetext{
${ }^{6}$ FOUCAULT, M. Segurança, território, população. Trad. Eduardo Brandão. São Paulo: Martins Fontes, 2008, p. 305.

${ }^{7}$ SENELlart, M. A Crítica da Razão Governamental em Michel Foucault. In: Tempo social, vol. 7, n. 1-2, outubro de 1995, p.2.
}

\begin{tabular}{|c|c|c|c|c|c|}
\hline intuitio & $\begin{array}{c}\text { ISSN } \\
1983-4012\end{array}$ & Porto Alegre & Vol.8 $-\mathrm{N}^{\mathrm{o}} .1$ & $\begin{array}{c}\text { Junho } \\
2015\end{array}$ & p.171-184 \\
\hline
\end{tabular}


Uma análise da razão de estado em Michel Foucault a partir do curso Segurança, Território e População

como que um amplo leque, partindo das formas propriamente privadas do desenvolvimento do problema da condução - a pergunta é: como se conduzir? ${ }^{8}$

Percebemos que após os movimentos de contraconduta surgiu como que uma intensificação da própria conduta, agora não somente no campo religioso, mas também no campo político. Surge o problema de como se conduzir, como conduzir alguém ou como deixar-se conduzir. É o que afirma Candiotto:

Para Foucault, as artes de governar que explodem no século XVI e se difundem até o final do século XVIII não são manuais de conselhos ao príncipe ou tratados de ciência política. Elas constituem diferentes possibilidades de governar os outros e de governar a si mesmo. Na pastoral católica e protestante, tem-se o governo das almas e das condutas; na pedagogia do século XVI, o problema do governo das crianças; na política, a questão do governo do Estado pelos príncipes. As questões fundamentais passam a ser: como se governar, como ser governado, como governar os outros, como fazer para ser o melhor governo possível? ${ }^{9}$

O problema da condução também é o problema de como governar, ou como o soberano deve governar seu território e seus súditos. O soberano tem que fazer algo mais que um pai de família, mais que um pastor, mas que Deus com relação à natureza. Segundo Helton Adverse "[A] Razão de Estado inaugura uma racionalidade política na qual a tarefa de governar deixa de ser referida a um elemento externo à dimensão política." ${ }^{10}$ Desse modo, faz-se necessário criar um novo modelo, uma nova racionalidade, a razão de Estado. "Importa frisar que a arte de governar se articula em torno de um tema importante à análise política: a razão de Estado, a aí não no sentido atual do termo, mas naquele relacionado à racionalidade da atuação estatal" ${ }^{\prime 1}$.

É dessa nova racionalidade que nos ocuparemos agora. Antes de compreendermos exatamente o que se constitui essa racionalidade é importante compreender o que é racionalidade para Foucault. Segundo Nildo Avelino: “[C]om o termo racionalidades Foucault entendia os conjuntos de prescrições calculadas e razoáveis que organizam instituições, distribuem espaços e regulamentam comportamentos; as racionalidades provocam uma série de efeitos sobre o real." ${ }^{\prime 2}$ Nesse sentido, a nova racionalidade

\footnotetext{
${ }^{8}$ FOUCAULT, M. Segurança, território, população. Trad. Eduardo Brandão. São Paulo: Martins Fontes, 2008 , p. 308.

${ }^{9}$ CANDIOTTO, Cesar. A governamentalidade política no pensamento de Foucault. In: Filosofia Unisinos, jan-abril de 2010, p. 10.

10 ADVERSE, Helton. Para uma Crítica da Razão Política: Foucault e a Governamentalidade. In: Estudos filosóficos, $n^{\circ}$ 4/2010, p. 18.

${ }^{11}$ MAIA, Antonio. Do biopoder à governamentalidade: sobre a trajetória da genealogia do poder. In: Currículo sem fronteiras, v.11, n.1, janeiro-junho de 2011, p. 65.

${ }^{12}$ AVELINO, Nilo. Governamentalidade e arqueologia em Michel Foucault. In: Revista brasileira de ciências sociais, v. 25, n. 74, 2010, s/p.
}

\begin{tabular}{|c|c|c|c|c|c|}
\hline intuitio & $\begin{array}{c}\text { ISSN } \\
1983-4012\end{array}$ & Porto Alegre & Vol.8 $-\mathrm{N}^{\mathrm{o}} .1$ & $\begin{array}{c}\text { Junho } \\
2015\end{array}$ & p.171-184 \\
\hline
\end{tabular}


presente na razão de Estado produziu inúmeros efeitos práticos sobre a vida das pessoas, o que consequentemente alterou a configuração do Estado.

Para tratar dessa temática, Foucault recupera em Palazzo o sentido originário do termo razão de Estado. Como em outros momentos o pensador francês se volta para tratados que foram importantes em determinados períodos históricos, mas que não ganharam grande projeção histórica. Esse é o caso de Palazzo, seus escritos tiveram importância num determinado tempo histórico, nesse caso específico na Itália, mas em seguida foram negligenciados.

Palazzo intenta compreender primeiro o que é razão, depois o que é Estado para enfim compreender o que se entende por razão de Estado. Razão aparece então em dois sentidos, um objetivo e outro subjetivo. Objetivamente é a essência inteira de uma coisa e subjetivamente é "certo poder da alma que permite, justamente, conhecer a verdade das coisas"13. Já Estado é compreendido a partir de quatro elementos: é um domínio; uma jurisdição; uma condição de vida; e a qualidade de uma coisa (qualidade que se opõe ao movimento). Nesse debate é importante a noção de República, que deve ser compreendida como um Estado nos quatros sentidos citados acima, essa afirmação ficará mais clara no decorrer do nosso texto.

Razão de Estado num sentido objetivo é o que é necessário para manter a integridade da República nos seus quatro sentidos. Já em seu sentido subjetivo razão de Estado é a arte que possibilita que se conheçam os meios para manter a tranquilidade de uma República. Está surgindo uma nova racionalidade própria ao Estado moderno capaz de manter, ampliar e fortalecer a ação do próprio Estado. É importante esclarecer que Foucault está realizando uma genealogia das práticas do Estado, mas não do Estado enquanto máquina burocrática. Nesse sentido, são as práticas do Estado que são ampliadas e complexificadas no período moderno. E são as práticas dos homens que são analisadas por Foucault.

Foucault recupera em Palazzo quatro características fundamentais da razão de Estado. Ao contrário do poder pastoral, a razão de Estado não tem nenhuma referência externa, seja natural ou divina. Como afirmamos o poder pastoral direciona-se sempre a um transcendente, a razão de Estado por sua vez, tem referência única e exclusivamente em si mesma. Assim chegamos à segunda característica da razão de Estado, ela é a essência do Estado, ou o saber que permite que o Estado possa ser mantido e consequentemente ampliado. Em terceiro lugar, a razão de Estado é "conservatória", nas palavras de Foucault, pois tem por objetivo primeiro manter o Estado em seu pleno funcionamento. Por fim, a razão de Estado é a finalidade do próprio Estado, não existe nenhuma outra finalidade externa ou superior, ou seja, é um fim em si mesma.

${ }^{13}$ FOUCAULT, M. Segurança, território, população. Trad. Eduardo Brandão. São Paulo: Martins Fontes, 2008, p. 342.

\begin{tabular}{|c|c|l|l|l|l|}
\hline intuitio & $\begin{array}{c}\text { ISSN } \\
1983-4012\end{array}$ & Porto Alegre & Vol.8 $-\mathrm{N}^{\circ} .1$ & $\begin{array}{c}\text { Junho } \\
2015\end{array}$ & p.171-184 \\
\hline
\end{tabular}


Nesse contexto cabe perguntar, como o fez Foucault, por que os indivíduos deveriam obedecer a um Estado que não propõe nenhuma finalidade a não ser ele mesmo? Não poderia haver um Estado que simplesmente intervenha quando necessário? Ou que solucione os eventuais problemas que possam surgir? A resposta a esse questionamento é negativa, pois a natureza humana é fraca, não seria capaz de manter a ordem e o bom funcionamento da sociedade sem um aparato externo, que apesar de ser fim em si mesmo, faz-se necessário.

Ainda nessa esteira argumentativa, o Estado, para o pensador francês, é fim em si mesmo, ao contrário do que eram os grandes Impérios que tinham por finalidade a construção de um Império universal capaz de abarcar a todos os povos, ou o que buscava a Igreja, a saber, ser uma instituição universal. Contudo, há um elemento que pode ser considerado como que certa "finalidade" do Estado, que claramente faz referência a Kant, a ideia de paz perpétua.

Vale dizer que a paz universal não será a consequência de uma unificação num império temporal ou espiritual, mas a maneira como diferentes Estados, se efetivamente as coisas funcionarem, poderão coexistir uns com os outros de acordo com um equilíbrio que impedirá justamente a dominação de um sobre os outros. A paz universal é a estabilidade adquirida na e pela pluralidade, por uma pluralidade equilibrada, totalmente diferente portanto da idéia do Império terminal. ${ }^{14}$

Se pudermos dizer que há uma finalidade nesse processo, isso necessariamente implica que exista uma pluralidade de Estados independentes e autônomos. O Império por sua vez tinha por objetivo a existência de um único Estado que pudesse dominar todos os demais territórios, impedindo que existisse espaço para a autonomia dos territórios submissos ao grande Império. Com a razão de Estado o princípio é que os diferentes Estados respeitem-se mutuamente, mas isso em nada impede a livre concorrência e até mesmo a dominação velada de uns Estados sobre os outros, isso é que conhecemos como liberalismo.

Apesar de evidenciar a ruptura entre poder pastoral e razão de Estado, Foucault faz uma relação entre os três principais temas do pastorado: salvação, lei e verdade com a razão de Estado. Para tratar da relação entre razão de Estado e salvação Foucault apresenta o conceito de golpe de Estado. É importante esclarecer o que se entende por golpe de Estado no século XVII. O golpe de Estado no século XVII é entendido como uma interrupção das leis e da legalidade. Rompe, nesse sentido, com o direito comum instituído.

Foucault pergunta se o golpe de Estado não seria um rompimento com a razão de Estado, visto romper com a legalidade. A resposta a essa pergunta é negativa, pois a própria razão de Estado não está subordinada totalmente à legalidade. O objetivo da razão de Estado é manter e ampliar o Estado, assim se

${ }^{14}$ FOUCAULT, M. Segurança, território, população. Trad. Eduardo Brandão. São Paulo: Martins Fontes, 2008, p. 348.

\begin{tabular}{|c|c|c|c|c|c|}
\hline intuitio & $\begin{array}{c}\text { ISSN } \\
1983-4012\end{array}$ & Porto Alegre & Vol.8 $-\mathrm{N}^{\circ} .1$ & $\begin{array}{c}\text { Junho } \\
2015\end{array}$ & p.171-184 \\
\hline
\end{tabular}


for necessário para alcançar esse objetivo, as leis podem ser suspensas. Nessa compreensão o golpe de Estado não é uma ruptura com a razão de Estado, mas é um elemento pertencente à razão de Estado, obviamente que, utilizado esporadicamente, quando assim o for necessário.

Mas, se o golpe de Estado é uma manifestação da razão de Estado, o que há de específico no entendimento de golpe de Estado no século XVII? A razão de Estado normalmente respeita as leis, não se opõe frontalmente a elas, desse modo o elemento diferencial do golpe de Estado é que há um rompimento fundamental com as leis constituídas e o surgimento de uma nova legalidade necessária para a sobrevivência do Estado. É por isso que Foucault afirma "o golpe de Estado é a automanifestação do próprio Estado."15

Há um conceito fundamental para compreender a ação do Estado no século XVII, o conceito de necessidade. Nesse raciocínio a política diz respeito às leis, mas sua relação principal é com a necessidade. Consequentemente o Estado pode romper com as leis se isso se manifestar necessário. Foucault cita Le Bret para ratificar a importância da necessidade na política do século XVII.

Tão grande é a força da necessidade que, como um deusa soberana, não tendo nada de sagrado no mundo, salvo a firmeza dos seus decretos irrevogáveis, põe sob seu poder todas as coisas divinas e humanas. A necessidade emudece as leis. A necessidade faz cessar todos os privilégios para se fazer obedecer por todo o mundo. ${ }^{16}$

O golpe de Estado, portanto, tem como primeira característica a necessidade, manifestada quando o próprio Estado estiver em risco. Segundo, o golpe de Estado é violento. A razão de Estado em sua ação corriqueira não é violenta, age em conformidade com a lei e a aplica ordinariamente sem maiores problemas. A violência se manifesta quando o Estado precisa sacrificar alguns para salvar a todos, nesse sendo, salvar a si mesmo. Ao contrário do poder pastoral que precisava salvar a todos e a cada um, a razão de Estado não precisa salvar a cada um individualmente, precisa mesmo é salvar o Estado, e se para isso for necessário pode sacrificar alguns, pois o importante é "preservar a justiça nas grandes coisas"17.

Nessa discussão é fundamental distinguir violência de brutalidade. A brutalidade é cometida por caprichos particulares, já a violência é cometida em nome das grandes coisas, mais especificamente para a manutenção do Estado, objetivo maior da razão de Estado. É parte da razão de Estado ser violenta, especialmente quando a necessidade exigir. Vemos novamente o poder da necessidade e como a política está subordinada às necessidades que o Estado lhe impõe.

${ }^{15}$ FOUCAULT, M. Segurança, território, população. Trad. Eduardo Brandão. São Paulo: Martins Fontes, 2008 , p. 350 .

${ }^{16}$ Le Bret, apud, FOUCAULT, M. Segurança, território, população. Trad. Eduardo Brandão. São Paulo: Martins Fontes, 2008, p. 351.

${ }^{17}$ FOUCAULT, M. Segurança, território, população. Trad. Eduardo Brandão. São Paulo: Martins Fontes, 2008 , p. 352.

\begin{tabular}{|c|c|c|c|c|c|}
\hline intuitio & $\begin{array}{c}\text { ISSN } \\
1983-4012\end{array}$ & Porto Alegre & Vol.8 $-\mathrm{N}^{\mathrm{o}} .1$ & $\begin{array}{c}\text { Junho } \\
2015\end{array}$ & p.171-184 \\
\hline
\end{tabular}


Por fim a terceira característica do golpe de Estado é a sua teatralidade. O golpe de Estado é uma necessidade da razão de Estado, mas precisa ser reconhecido por todos como necessário, por isso seu aspecto teatral. Quando da sua manifestação logo deve ser reconhecido como necessário para a manutenção do Estado, precisa ser deflagrado à luz do dia, para que todos percebam que está sendo produzido pela razão de Estado e, portanto, é necessário. Sua aparição teatral o faz aparecer solenemente, o que permite que se escondam seus procedimentos e seus encaminhamentos. As palavras de Naudé, citadas por Foucault, apresentam poeticamente o que era o golpe de Estado.

[...] nos golpes de Estado, vê-se o relâmpago cair antes de ouvi-lo troar nas nuvens. (...) as matinas são ditas antes de serem soadas, a execução precede a sentença; tudo se faz a judaica; (...) um recebe o golpe que pensava dar, outro morre pensando estar em segurança, outro mais sofre como não imaginava, tudo se faz de noite, na obscuridade, entre névoas e as trevas. ${ }^{18}$

Em nome da manutenção do Estado, é permitida à razão de Estado sacrificar, prejudicar, amputar, escolher, enfim ser injusta nas pequenas coisas. Como a manutenção do Estado está em constante perigo, o Estado pode agir de maneira obscura para garantir sua sobrevivência. Portanto a relação da razão de Estado com o primeiro tema do pastorado, a salvação, é marcada pela desobediência das leis, pela violência e pela teatralidade, todos esses aspectos possuem íntima ligação com a necessidade de manter e ampliar o Estado.

O segundo tema do pastorado que Foucault relaciona à razão de Estado é o tema da obediência. Para apresentar essa relação o pensador francês apresenta o problema das sedições, ou dos perigos que estão presentes a todo o momento nas relações do Estado moderno. A inspiração para tratar desse tema vem de Bacon num tratado pouco conhecido intitulado Ensaio sobre sedições e distúrbios.

Apesar das sedições serem um problema constante no Estado moderno costumam manifestar-se, especialmente, em tempos de calmaria e equilíbrio, desse modo, deve-se desconfiar desses períodos, pois é justamente nesse espaço de tempo que estão os perigos para o Estado. Foucault apresenta uma série de acontecimentos que podem caracterizar um perigo ao Estado, como a circulação excessiva de rumores, a inversão de valores e a má circulação das ordens. Todos esses são sinais de que fortes sedições estão a caminho e o Estado deve se preparar para enfrentá-las e minimizar seus efeitos.

$\mathrm{Na}$ análise de Bacon existem duas causas de sedições, as materiais e as ocasionais. As causas materiais possuem dois vetores, a pobreza insuportável e o descontentamento, ou os chamados fenômenos de opinião. Os últimos ocorrem quando há um descontentamento geral com as ações do Estado. Já as causas ocasionais ocorrem quando são realizadas mudanças naquilo que normalmente permanece

\footnotetext{
${ }^{18}$ NAUDÉ, apud FOUCAULT, M. Segurança, território, população. Trad. Eduardo Brandão. São Paulo: Martins Fontes, 2008, p. 356.
}

\begin{tabular}{|c|c|c|c|c|c|}
\hline intuitio & $\begin{array}{c}\text { ISSN } \\
1983-4012\end{array}$ & Porto Alegre & Vol.8 $-\mathrm{N}^{\circ} .1$ & $\begin{array}{c}\text { Junho } \\
2015\end{array}$ & p.171-184 \\
\hline
\end{tabular}


inalterado, por exemplo, a mudança na religião ou um grande aumento de preços. Essas mudanças afetam diferentes camadas da sociedade e a união dessas diferentes camadas se torna perigosa para a manutenção do Estado.

Se as sedições possuem causas consequentemente possuem remédios. A fim de evitar sedições os remédios devem atuar diretamente nos elementos capazes de gerar uma sedição, a saber, a cabeça e a barriga. Para evitar os males advindos da barriga é necessário eliminar a pobreza, ou seja, garantir que todos possam ter condições dignas de vida. Com relação às sedições que surgem da cabeça, segundo Bacon, é preciso evitar que os grão-senhores unam-se ao povo. Visto que o povo é lento para se revoltar e a nobreza possui número insuficiente para se colocar contra o Estado, o perigo advém quando se une a rapidez da nobreza com a força numerosa do povo. Para evitar essa sedição é preciso estabelecer uma distância considerável entre os nobres e o povo para que essa união nunca se produza.

Tudo isso Foucault apresenta para afirmar que com o advento da razão de Estado, governar é governar o povo. Os problemas com a nobreza são relativamente fáceis de resolver, "ou se os compra, ou se os executa", ou seja, o problema do governo não é mais os inimigos do príncipe como afirmava Maquiavel, mas é o povo. Outro elemento que corrobora com essa afirmação é o de que o cálculo que o governo precisa fazer não é com os qualitativos do príncipe, mas com os elementos da economia, ou seja, com todas as riquezas que circulam, com os impostos, com os ganhos das pessoas reais que habitam o Estado e assim por diante. A preocupação é com a situação das pessoas, nesse sentido, o governo precisa manipular a economia e a opinião das pessoas.

Por fim o último elemento do poder pastoral que Foucault relaciona com a razão de Estado e que passamos a analisar agora é o tema da verdade. A pergunta que surge é: o que é necessário saber para governar? É nesse momento que surge a estatística, como artifício que permite o conhecimento dos elementos necessários para a manutenção do Estado. Não é suficiente conhecer a lei e aplicá-la, é necessário conhecer as realidades todas do Estado. Além disso, o Estado deve intervir sobre a consciência das pessoas, tornando-as legitimadoras da sua ação. Ocorre como que uma instrumentalização da opinião pública para que apoie a ação do governo em âmbito econômico, bem como e principalmente no âmbito político.

Após relacionar os temas do pastorado com a razão de Estado Foucault se volta novamente para o desenvolvimento da razão de Estado na modernidade. Para o pensador francês o desafio dessa nova racionalidade não é só manter o Estado, mas também o desenvolvimento de uma dinâmica de forças que envolvem a relação dos Estados modernos entre si. A partir dessa necessidade é que surgem dois novos dispositivos, o dispositivo diplomático-militar e a polícia.

O dispositivo diplomático-militar surge exatamente para garantir uma relação equilibrada entre os diferentes Estados. É necessário alcançar esse equilíbrio, pois todos os Estados são autônomos em suas

\begin{tabular}{|c|c|c|c|c|c|}
\hline intuitio & $\begin{array}{c}\text { ISSN } \\
1983-4012\end{array}$ & Porto Alegre & Vol.8 $-\mathrm{N}^{\mathrm{o}} .1$ & $\begin{array}{c}\text { Junho } \\
2015\end{array}$ & p.171-184 \\
\hline
\end{tabular}


decisões e em seus territórios, entretanto, sua expansão tem que estar limitada no nível que não provoque os outros Estados para não acabar produzindo um grande conflito que origine o desaparecimento do próprio Estado. Foucault usa o caso europeu para exemplificar essa nova relação entre os Estados modernos. A Europa se constituiu exatamente para equilibrar a relação entre os diferentes Estados que a compõem e estabelecer algumas normas para que nenhum Estado simplesmente destruísse a outrem que fosse mais fraco. Contudo, é permitida a expansão para além Europa, e nesse caso a colonização além-mar é perfeitamente aceitável. Nessa linha de raciocínio o domínio de um Estado sobre o outro não é aceitável no interior da Europa, mas fora dessas fronteiras é perfeitamente aceitável e até mesmo louvável.

O segundo dispositivo que surge nessa nova dinâmica de forças é a polícia. É claro que nos séculos XVII e início do século XVIII o sentido de polícia é diverso de como hoje a entendemos. É o que afirma Foucault.

A partir do século XVII, vai-se começar a chamar de 'polícia' o conjunto dos meios pelos quais é possível fazer as forças do Estado crescerem, mantendo ao mesmo tempo a boa ordem desse Estado. Em outras palavras, a polícia vai ser o cálculo e a técnica que possibilitarão estabelecer uma relação móvel, mas apesar de tudo estável e controlável, entre a ordem interna do Estado e o crescimento das suas forças. ${ }^{19}$

Em outros termos a polícia é responsável por manter a grandeza do Estado. O grande instrumento da polícia para alcançar esse objetivo é a estatística, essa permite que o Estado tenha conhecimento acerca das coisas que pertencem ao Estado, mas em especial das pessoas, o que elas fazem e quais suas ocupações. Enfim, permite um controle maior sobre as ações dos sujeitos do Estado. Foucault resume a ação da polícia da seguinte maneira: regulação da ação dos homens entre si, ou seja, regulação das ações públicas dos indivíduos que poderiam influenciar negativamente a ação de outros indivíduos. Nas palavras de Foucault: "Turquet usa uma expressão notável: o homem é o verdadeiro objeto da polícia."20

A partir de meados do século XVIII a noção de polícia sofre alguns abalos até se tornar o que hoje entendemos por polícia. Os grandes críticos do Estado de polícia foram os economistas, pois criaram uma nova racionalidade governamental, a economia, ainda presente no interior da razão de Estado, mas com novos objetivos. Para essa nova racionalidade há como que uma naturalidade na ação da população, desse modo, o Estado não deve regulamentar, mas gerir, no sentido que essa naturalidade seja bem direcionada. Surgem novos elementos de governamentalidade: a sociedade, a economia, a população, o território, a segurança e a liberdade. São esses novos elementos que permitem o surgimento do que chamamos de liberalismo. Essa é uma temática amplamente trabalhada por Foucault, contudo esse não é nosso objetivo,

${ }^{19}$ FOUCAULT, M. Segurança, território, população. Trad. Eduardo Brandão. São Paulo: Martins Fontes, 2008 , p. 421.

${ }^{20}$ FOUCAULT, Michel. “Omnes et singulatim”: vers une critique de la raison politique. In.: Dits et Écrits. Vol. IV. Editado por D. Defert, F. Ewald e J. Lagrange. Paris: Gallimard, 1994, p. 155.

\begin{tabular}{|c|c|c|c|c|c|}
\hline intuitio & $\begin{array}{c}\text { ISSN } \\
1983-4012\end{array}$ & Porto Alegre & Vol.8 $-\mathrm{N}^{\circ} .1$ & $\begin{array}{c}\text { Junho } \\
2015\end{array}$ & p.171-184 \\
\hline
\end{tabular}


apenas apresentamos os elementos essenciais para que se possa compreender a mudança no conceito moderno de polícia. A polícia e dispositivo diplomático-militar serviram para afirmar a razão de Estado, permitindo a consolidação do Estado moderno. Toda essa análise feita por Foucault visa compreender as ações humanas que permitiram a consolidação do Estado.

\section{Considerações finais}

Foucault finaliza reafirmando que o Estado deve ser estudado a partir da prática dos homens. Da mesma forma a razão de Estado, que buscamos investigar em nosso artigo, se constitui a partir da prática dos homens que a transformaram de acordo com as necessidades que vislumbravam para o Estado. A razão de Estado sempre esteve a serviço da manutenção e ampliação do Estado, claro que com o advento do liberalismo essa relação sofreu algumas transformações, o que de certa forma enfraqueceu o Estado e fortaleceu as grandes corporações que dominam o poder econômico no mundo contemporâneo.

A genealogia da razão de Estado nos permite perceber que o Estado se constitui a partir das práticas das pessoas, desse modo, se queremos mudar o Estado, precisamos antes de tudo mudar as nossas práticas. O Estado não é um ente abstrato, muito menos uma instituição que surge das vontades contratantes que decidiram fundá-lo, é o resultado de um amplo processo, ou dito de outra maneira, de uma complexa rede de práticas humanas. Afirma o pensador francês:

O Estado é, ao mesmo tempo, o que existe e o que ainda não existe suficientemente. E a razão de Estado é precisamente uma prática, ou antes, uma racionalização de uma prática que vai se situar entre um Estado apresentado como dado e um Estado apresentado como a construir e a edificar. A arte de governar deve, então, estabelecer suas regras e racionalizar suas maneiras de fazer propondo-se como objetivo, de certo modo, fazer o dever-ser do Estado tornar-se ser. O dever-fazer do governo deve se identificar com o dever-ser do Estado. O Estado tal como é dado - a ratio governamental - é o que possibilitará, de uma maneira refletida, ponderada, calculada, fazê-lo passar ao seu máximo de ser. $^{21}$

Foucault não nos fornece soluções para que busquemos uma mudança, essa se constitui em uma crítica constante ao seu pensamento. Contudo, seu método genealógico nos permite mapear a origem daquilo que queremos mudar, o que sem dúvida, é um poderoso instrumento para iniciar uma mudança. Sabemos que uma mudança é um processo lento e gradual e que na maioria das vezes não há uma receita pronta, ou seja, precisa ser construída e lapidada. Nesse sentido, o pensador francês não nos fornece nenhuma receita, mas alguns importantes elementos para que a mudança possa ser iniciada.

${ }^{21}$ FOUCAULT, Michel. Nascimento da Biopolítica. Curso dado no Collège de France (1978-1979). Trad. Eduardo Brandão. São Paulo: Martins Fontes, 2008, p.6.

\begin{tabular}{|c|c|c|c|c|c|}
\hline intuitio & $\begin{array}{c}\text { ISSN } \\
1983-4012\end{array}$ & Porto Alegre & Vol.8 $-\mathrm{N}^{\mathrm{o}} .1$ & $\begin{array}{c}\text { Junho } \\
2015\end{array}$ & p.171-184 \\
\hline
\end{tabular}


Odair Camati

Uma análise da razão de estado em Michel Foucault a partir do curso Segurança, Território e População

\section{Referências}

ADVERSE, Helton. Para uma Crítica da Razão Política: Foucault e a Governamentalidade. In: Estudos filosóficos, $n^{\circ} 4 / 2010$.

AVELINO, Nilo. Governamentalidade e arqueologia em Michel Foucault. In: Revista brasileira de ciências sociais, v. 25, n. $74,2010$.

CANDIOTTO, Cesar. A governamentalidade política no pensamento de Foucault. In: Filosofia Unisinos, jan-abril de 2010.

DUARTE, André de Macedo. Foucault e a governamentalidade: genealogia do liberalismo e do Estado Moderno. In: SelectedWords, 2011.

FOUCAULT, M. Segurança, território, população. Trad. Eduardo Brandão. São Paulo: Martins Fontes, 2008.

. "Omnes et singulatim": vers une critique de la raison politique. In.: Dits et Écrits. Vol. IV. Editado por D. Defert, F. Ewald e J. Lagrange. Paris: Gallimard, 1994.

. Nascimento da Biopolítica. Curso dado no Collège de France (1978-1979). Trad. Eduardo

Brandão. São Paulo: Martins Fontes, 2008.

MAIA, Antonio. Do biopoder à governamentalidade: sobre a trajetória da genealogia do poder. In: Currículo sem fronteiras, v.11, n.1, janeiro-junho de 2011.

SANTOS, R. Eleandro dos. Do governo pastoral à governamentalidade: crítica da razão política em Michel Foucault. In: Poros, vol. 1, n. 2, 2009.

SENELLART, M. A Crítica da Razão Governamental em Michel Foucault. In: Tempo social, vol. 7, n. 1-2, outubro de 1995. http://dx.doi.org/10.1590/ts.v7i1/2.85117

Recebido em: 08/09/2014

Aprovado para publicação em: 17/04/2015

\begin{tabular}{|c|c|l|l|l|l|}
\hline intuitio & $\begin{array}{c}\text { ISSN } \\
1983-4012\end{array}$ & Porto Alegre & Vol.8 $-\mathrm{N}^{\mathrm{o}} .1$ & $\begin{array}{c}\text { Junho } \\
2015\end{array}$ & p.171-184 \\
\hline
\end{tabular}

